Proceedings

\title{
Consumer Preferences for New Products: Eye Tracking Experiment on Labels and Packaging for Olive Oil Based Dressing ${ }^{\dagger}$
}

\author{
Marco Fazio ${ }^{1, *}$, Antonella Reitano ${ }^{2}$ and Monica Rosa Loizzo ${ }^{1}$ \\ 1 Department of Pharmacy, Health and Nutritional Sciences, University of Calabria, 87036 Rende CS, Italy; \\ monica_rosa.loizzo@unical.it \\ 2 Department of Business Administration and Law, University of Calabria, 87036 Rende CS, Italy; \\ a.reitano@unical.it \\ * Correspondence: marco.fazio@unical.it \\ + Presented at the 1st International Electronic Conference on Food Science and Functional Foods, \\ 10-25 November 2020; Available online: https://foods_2020.sciforum.net/
}

Citation: Fazio, M.; Reitano, A.; Loizzo, M.R. Consumer Preferences for New Products: Eye Tracking Experiment on Labels and Packaging for Olive Oil Based Dressing. Proceedings 2021, 70, 59. https://doi.org/10.3390/foods_202008124

Published: 13 November 2020

Publisher's Note: MDPI stays neutral with regard to jurisdictional claims in published maps and institutional affiliations.

Copyright: (C) 2020 by the authors. Licensee MDPI, Basel, Switzerland. This article is an open access article distributed under the terms and conditions of the Creative Commons Attribution (CC BY) license (http://creativecommons.org/licenses/by/4.0/)
Abstract: The product can be defined as a "basket of attributes" which provides the customer with the functional value specific to that class of product, as well as a set of secondary values (called benefits or services) which may be necessary or added. These additional services differentiate the brands and may have determining influence on customer's preferences. Within the "GLASOIL" project (ID CUP J77H18000280006) the research activity focused on the development of the new product (olive oil based dressing) as a whole through the evaluation of the basket of attributes. Once the main reference targets had been defined, the survey focused on the expectations and evaluations of potential customers with respect to the new product. Investigating consumer preferences, before a product is launched on the market, is fundamental for companies and makes it possible to reduce failure rates. Through the creation of a focus group, the preferences and opinions of potential consumers on a new olive oil-based condiment were investigated. From the results obtained, different combinations of packaging were elaborated, subsequently used as graphic stimuli to carry out tests with eye tracking, aimed at verifying the presence of possible weak points of the packaging before launching the product on the market. The results show that, for this specific type of product, consumers preferred a transparent package that makes the product visible inside, characterized by elegant lines and equipped with a drop breaking cap. On the label, on the other hand, consumers, in addition to the information required by law, wanted to see the origin of production and instructions on possible use. In conclusion, the analysis with eye tracking showed that images with elements such as a hand using the product, prove to be "winning", as they attract the observer's attention. Eye tracking analysis also confirmed that men and women look at the packaging and label differently.

Keywords: consumer's preferences; eye tracking; new food products; packaging; label

\section{Introduction}

The product can be defined as a "basket of attributes" which provides the customer with the functional value specific to that class of product, as well as a set of secondary values (called benefits or services) which may be necessary or added [1]. The additional services required are the production methods of the basic service and everything that accompanies the basic service (packaging, delivery, payment terms, after-sales services, etc.). The necessary added services, on the other hand, are utilities not linked to the basic 
service, offered in addition by the brand and representing an important element of distinction. These additional services differentiate the brands and may have determining influence on customer's preferences.

In order to have a market, a product must meet the needs of consumers [1]. For the launch of a new product on the market, innovation decisions are complex and risky, but fundamental for the survival and development of the company [1]. According to Barreyre, 1980 [2], an innovation can be divided into three elements:

- a need to be satisfied or a function to be performed;

- $\quad$ the concept of an object that satisfies the need;

- the set of inputs, including existing knowledge, materials and available technology, that enable the concept to become operational.

The risk associated with innovation will depend on two factors: the degree of originality and complexity of the concept, which will determine the market receptivity and transfer costs to be paid by the user (market risk), and the degree of technological innovation linked to the new concept, which will determine the technical feasibility of the innovation (technological risk). To these intrinsic risk factors must be added the degree of familiarity of the company with the market and the technology in question (strategic risk).

In the fast-moving consumer goods (FMCG) sector, the role of the consumer is that of those who respond and express themselves only when questioned. It is up to the producer to obtain information on articulated or latent needs for new products and to develop an appropriate product idea [1-3].

The new product under study, is a seasoning based on extra virgin olive oil, less dense and more viscous than a classic icing. Compared to the dressings already on the market, this one, is produced with excellent monovarietal extra virgin olive oils from $\mathrm{Ca}$ labria, specifically belonging to the "Coratina" cultivar. There are currently no pure olive oil dressings on the market, but rather mixtures based on oil and vinegar or flavored vinaigrettes.

The main objectives of the research are: (a) to investigate the preferences and opinions of potential consumers regarding a new seasoning based on extra virgin olive oil; (b) to explore the impact of consumers' visual attention on the packaging and label. In the first case, a focus group was carried out, while in the second case, an analysis through the use of eye tracking. The focus group is a methodology of qualitative analysis that consists of organizing a meeting with small groups of people to discuss a specific topic [4]. In the marketing field, it is used to find out consumers' preferences and opinions about brands, products, packaging. Eye tracking is particularly used in neuromarketing studies and is considered to be one of the most powerful means to determine individual choices [5]. In the analysis of a packaging, it makes it possible to highlight the existence of elements that are then fundamental during the decision-making processes and allows hypotheses to be made about the elements of success and the presence of weak points before the product is launched on the market. Consumers typically make choice decisions within a few seconds; thus, they may not attend to all the information available on the food package [6]. Generally, some information is selected to be processed further while the rest is lost, and, in most cases, consumers are not even aware of its presence on the label [7].

\section{Materials and Methods}

\subsection{Focus Group: Objectives, Sample, Procedure and Data Analysis}

The survey through the focus group was carried out to investigate the preferences and opinions of potential consumers in relation to the new product, before the market launch of the same. The aim was to stimulate interaction between the participants. Due to recent government regulations for the containment of the Covid-19 virus, the focus group was conducted online, using Skype.

Participants were recruited to represent the reference targets identified for the use of the product. The new product is proposed as an ideal condiment for various dishes or to 
garnish and decorate dishes. Therefore, intended for both domestic and professional use, for this reason the main targets are large distribution (domestic use) and the Ho.Re.Ca. (professional use). For home users, the only requirement was to cook daily or be passionate about cooking. Distribution by gender and age group was convenient.

A single focus group with two moderators has been created; the single form is the most common one, where the participants dialogue on a given topic. The presence of the double moderator allows one to lead the session and the other to support the session. Before the session, the moderators prepared a list of questions by topic. The debate started with a short "warm-up" phase, where the moderators tried to put all participants at ease. Then the product and potential market were presented. The debate, which lasted just over an hour, was recorded and, subsequently, completely transcribed by the researchers who, however, took notes of what was said by the participants during the session. The transcribed material was examined by applying thematic analysis [8], a process involving the identification of themes through "careful reading and re-reading of data" [9]. This is a form of recognition of models within the data, in which emerging themes become the categories for analysis. Through the encoding of information, data are organized to identify and develop themes from the data. In the first phase of the process, the participants' comments and reflections have been examined and associated to one or more of the themes identified. In a second phase, the information was further examined, which produced a series of sub-themes, compared to the initial ones.

\subsection{Eye tracking Analysis}

With eye tracking you can record the dilation and contraction of the pupils, and you can achieve an effective eye tracking capable of identifying what you are observing and with what level of attention. The usability of websites [10], product packaging, advertising, protection brands and food labels [11-13] are among the main objects of study with this technology.

With regard to the analysis of a packaging and its label, the observation through this technology, makes it possible to formulate hypotheses on the elements of success and the presence of possible weak points before the product is launched on the market.

The results of the focus group made it possible to elaborate different packaging combinations, to be used as graphic stimuli for the eye tracking test. Two different packaging models (A and B) have been created, in three different combinations (Figures 1 and 2). Both models were characterized by a squeezable packaging equipped with a drop broking cap.

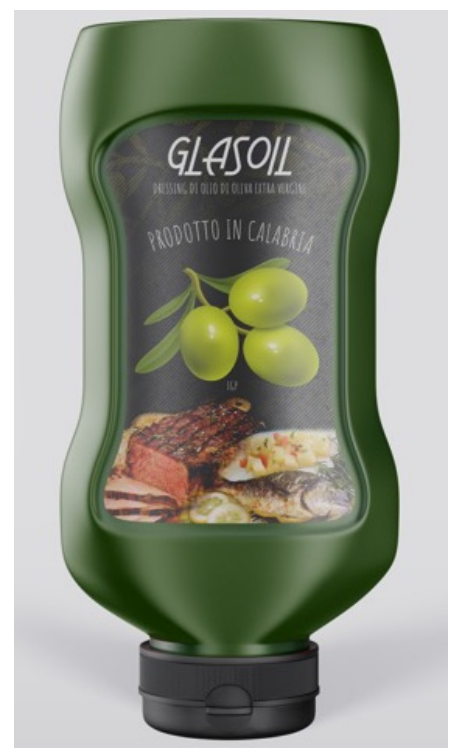

Combination 1

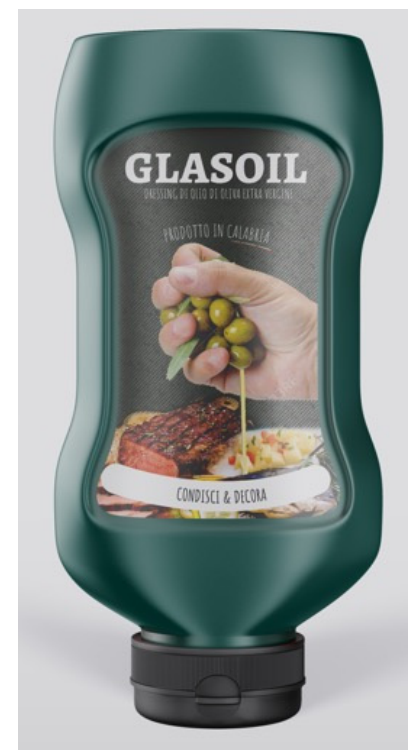

Combination 2

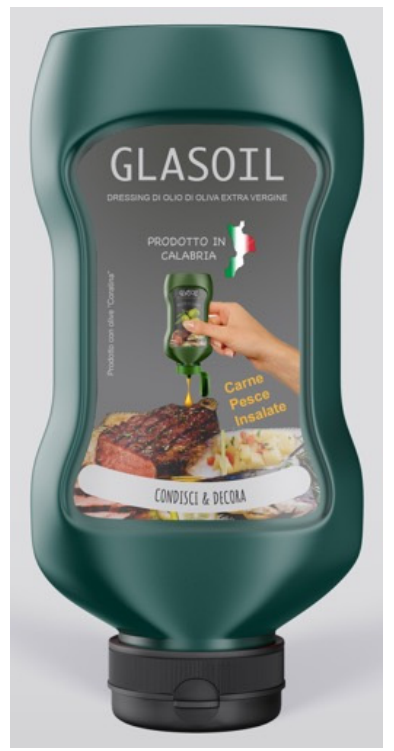

Combination 3

Figure 1. Packaging model " $\mathrm{A}$ " in three combinations (source: our processing). 


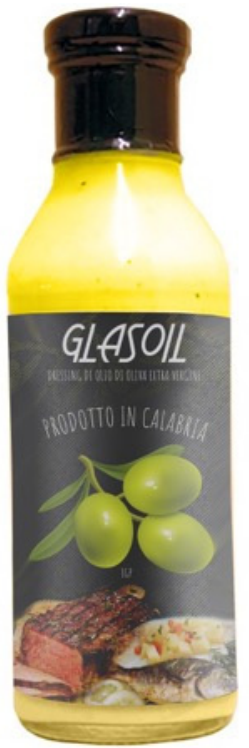

Combination 1

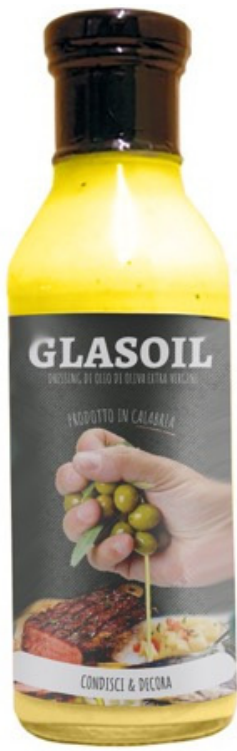

Combination 2

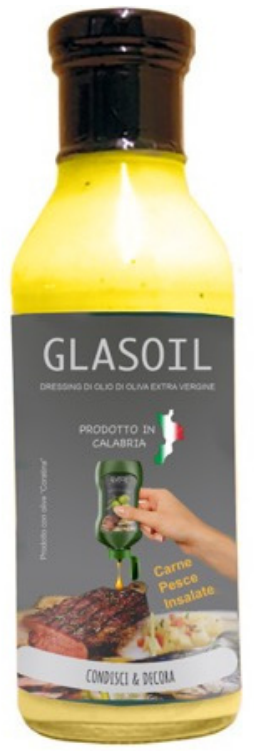

Combination 3

Figure 2. Packaging model " $\mathrm{B}$ " in three combinations (source: our processing).

Through eye tracking analysis and the subsequent debrief survey, we tried to understand what attracted consumers' attention most, arousing particular emotions or memories. For the analysis of the eye movement data, we defined a set of areas of interest (AOIs) to capture the eye fixations.

A sample of convenience was used to carry out the survey. No special requirements were asked the participants. Fifteen individuals, male and female $(40 \%$ men and $60 \%$ women), average age 39.73 years, were divided into three groups. Each group observed packaging $\mathrm{A}$ and $\mathrm{B}$ in the same combination.

After the eye tracking test, participants were asked to answer simple questions, such as:

- what type of product is it?

- $\quad$ what type of use do you suppose for the product?

- $\quad$ are the observed products the same?

- $\quad$ which of the two proposals did you prefer and why?

Due to recent government regulations on the containment of the Coronavirus (Covid19), the eye tracking experiment was not carried out in the laboratory, but with a similar online eye tracking system. Specifically, the RealEye system (https://www.realeye.io/), with educational license, was used, a cloud-based solution for neuroscientists that allows creating experiments, tracking participants, and analyzing the data-all in one place, online. RealEye is a member company of NmsBa (Neuromarketing scinece and Business association), winner of the "Best Tech Achievement" aword in 2017 (Hotjar XAward), has clients from 38 countries worldwide and over 41 thousand participants in the experiments. RealEye uses the computing power of a regular PC/laptop to run AI (Deep neural network) that analyzes images coming from a webcam. The AI detects the panelist's face, pupils and predicts a gaze point. Everything is performed entirely in a web browser in real-time. Panelists do not have to worry about their privacy as no image nor sound is sent to servers. The only data stored are the gaze point predictions from the AI in the form of basic text data similar to “Timestamp: 10, GazePointX: 200, GazePointY: 330". RealEye studies are proven to be around 110 px accurate $(\sim 1.5 \mathrm{~cm})$ with an average viewing angle error of $\sim 4.17$ degrees. This allows analyzing users interaction on a website with precision reaching the size of a single button. Data is captured with a sampling rate of up to $60 \mathrm{~Hz}$ (depends on a webcam and internet connection). 
A qualitative analysis of the heatmaps was carried out. The post-test interview data were analysed using spreadsheets.

\section{Results and Discussions}

The packaging and labels used for the analysis with eye tracking were made on the basis of the focus group results (for details see Figures 1 and 2).

\subsection{Graphic Stimulus A1-B1}

The first group of participants observed the graphic stimuli A and B in combination 1 , with the following results (Figure 3).

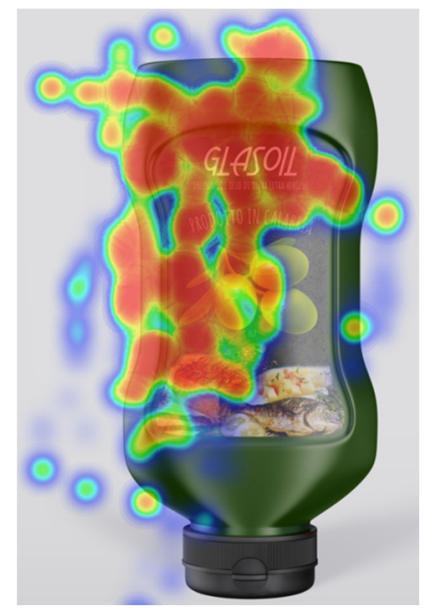

Graphic stimulus A1

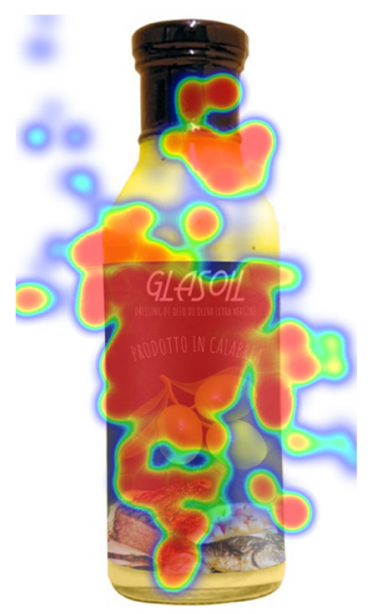

Graphic stimulus B1

Figure 3. Heatmap graphic stimulus A1 and B1(our processing).

The A1 packaging showed a higher concentration of fixations in the area of interest with the product name and in the AOI with the image of the olives. The profile of the packaging (especially the ergonomic part) and the wording "Made in Calabria" were particularly observed. Men have been more attracted by the image of the olives, while women to the area of interest with the representations of the dishes on which to use the dressing.

Stimulus B1, has been observed uniformly from top to bottom (not only the label but also the neck of the bottle with the product visible for the transparency of the wrapping). Women were more attentive than men to all the details of the label and packaging.

\subsection{Graphic Stimulus A2-B2}

The second group of participants observed the graphic stimuli A and B in combination 2, with the following results (Figure 4).

Graphic stimulus A2 showed a high intensity of fixations in the AOI of the product name, in the AOI with the figure of the hand squeezing the olives and on the images of the dishes on which the dressing is to be used. Compared to stimulus A1, the presence of the "hand" squeezing the olives captured the attention of the participants. The flow of pressed product from the olives towards the dishes, guides the participants' gaze downwards, thus shifting their attention to this area of interest.

In the graphic stimulus B2, in addition to the label, the neck and the bottle cap were observed particularly. The label is observed in the same way as the A2.

Few differences in observation between men and women; men have been more attracted by the wording "Dressing and Decorating". In the case of the B2 model, women were more focused on design and content, visible through the transparent bottle. 
The debrief survey revealed a preference for this second packaging (B2) over the first (A2), given the particularity of the shape and the possibility of seeing the product contained in it.

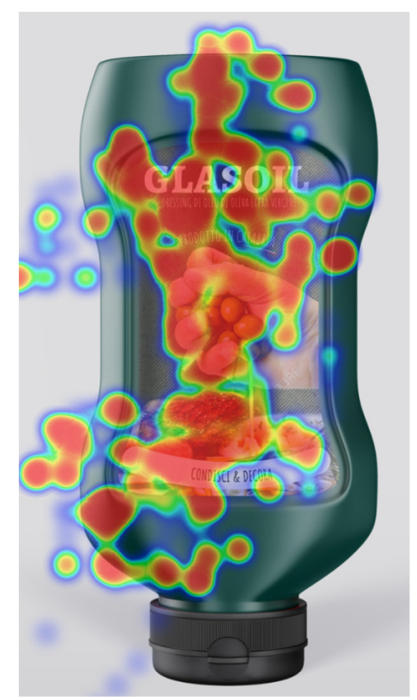

Graphic stimulus A2

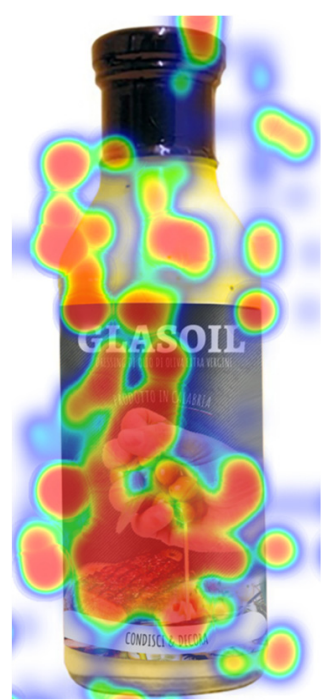

Graphic stimulus B2

Figure 4. Heatmap graphic stimulus A2 and B2 (our processing).

\subsection{Graphic Stimulus A3-B3}

The third group of participants observed the graphic stimuli A and B in combination 3 , with the following results (Figure 5).

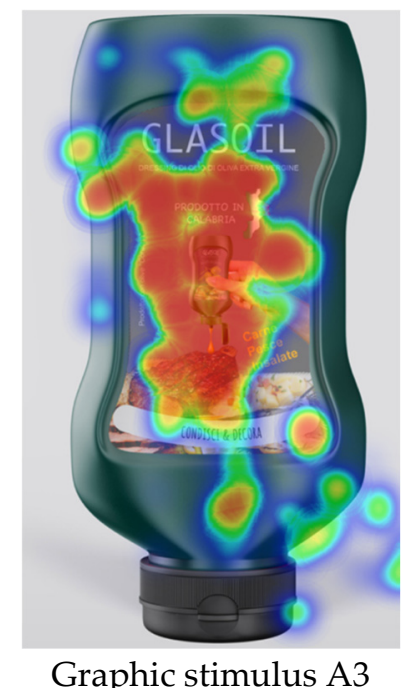

Graphic stimulus A3

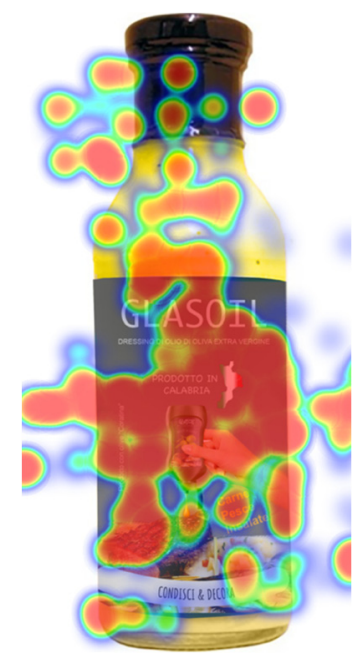

Graphic stimulus B3

Figure 5. Heatmap graphic stimulus A3 and B3 (our processing).

In the first case (stimulus A3), the area of greatest attraction was the central one, representing a hand squeezing a dressing pack on some dishes. The fixations in the section containing the wording "Made in Calabria" and the graphic icon of the Calabria region were very intense. On the contrary, there were fewer fixations on the AOI with the name of the product and the wording "Dressing of extra virgin olive oil".

For the A3 stimulus women were more attentive to the details of the label. Women followed an " $\mathrm{F}$ " pattern of observation; men, on the other hand, observed the label from top to bottom in the middle section, little attention to the product descriptions. 
In the case of stimulus B3, as before, this combination drew attention to the packaging and label. The debrief showed that this type of label is able to provide a clearer idea of the type of product under consideration.

\section{Conclusions}

This study confirmed the importance of the information on the label, highlighting how much the materials, shape and colours of the packaging can influence the possible choices of consumers. Very often, the same information, must be communicated in a different form on the same label if the product is destined to different targets at the same time [10-12].

This study confirmed that, for this specific type of product, consumers preferred a transparent package that makes the product visible inside, characterized by elegant lines and equipped with a drop breaking cap. The participants saw in this packaging a high quality product and this confirms that the material, the design and the ergonomics of a packaging are elements that can transfer certain information about the product and how it is intended to be perceived [14].

On the label, on the other hand, consumers, in addition to the information required by law, wanted to see the origin of production and instructions on possible use.

In conclusion, the analysis with eye tracking showed that images with elements such as a hand using the product, prove to be "winning", as they attract the observer's attention. Eye tracking analysis also confirmed that men and women look at the packaging and label differently.

Author Contributions: M.F. carried out the overall project design experimental work, M.F. and A.R. carried out the experiments and analysed the results. M.R.L. assisted the experimental work and provided funding acquisition. All authors conceptualized aspects of the project and assisted in the revision and editing of the manuscript. All authors have read and agreed to the published version of the manuscript.

Funding: This research was funded by POR CALABRIA FESR-FSE 2014-2020, Research Project "GLASOIL - Glassa innovativa a base di olio d'oliva" (CUP J77H18000280006).

Institutional Review Board Statement: Not applicable.

Informed Consent Statement: Informed consent was obtained from all subjects involved in the study.

Data Availability Statement: The data presented in this study are available on request from the corresponding author.

Conflicts of Interest: The authors declare no conflict of interest.

\section{References}

1. Lambin, J.J. Market-Driven Management. Marketing Strategico e Operativo, 6th ed.; McGrawHill: Milano, Italy, 2012; ISBN 97888-386-6728-2.

2. Barreyre, P.Y. Typologie des innovations. Reveu Francaise de Gestion 1980, 24, 9-15.

3. Von Hyppel, E. Successful Industrial Products from Customer Ideas. J. Mark. 1978, 1, 39-49.

4. Wilkinson, S. Ricerca sui focus group. In Ricerca Qualitativa: Teoria, Metodo e Pratica; Silverman, D., Ed.; Sage Publications: Thousand Oaks, CA, USA, 2004; pp. 177-199.

5. Balcombe, K.; Fraser, I.; McSorley, E. Visual attention and attribute attendance in multi-attribute choice experiments. J. Appl. Econ. 2015, 30, 447-467, doi:10.1002/jae.2383.

6. Milosavljevic, M.; Cerf, M. First attention then intention: Insights from computational neuroscience of vision. Int. J. Advert. 2008, 27, 381-398, doi:10.2501/S0265048708080037.

7. Oliveira, D.; Machín, L.; Deliza, R.; Rosenthal, A.; Walter, E.H.; Giménez, A.; Ares, G. Consumers' attention to functional food labels: Insights from eye-tracking and change detection in a case study with probiotic milk. LWT Food Sci. Technol. 2016, doi:10.1016/j.lwt.2015.11.066.

8. Boyatzis, R. Transforming Qualitative Information: Thematic Analysis and Code Development; Sage Publications: Thousand Oaks, CA, USA, 1998.

9. Rice, P.; Ezzy, D. Metodi di Ricerca Qualitativa: Un Focus Sulla Salute; Oxford University Press: Melbourne, Australia, 1999. 
10. Reitano, A.; Fazio, M. Eye-tracking and web usability. In Proceedings of the 11th International Scientific Conference “Digital Economy and Blockchain Technologies", Varna, Bulgaria, 29-30 June 2018; pp. 253-263, ISBN 978-619-7026-28-3.

11. Reitano, A.; Fazio, M.; Taylor, D.W. Traceability of food products in global gastronomic tourism. Symph. Emerg. Issues Manag. 2016, 2, 46-59, doi:10.4468/2016.2.06reitano.fazio.taylor.

12. Reitano, A.; Fazio, M. An eye tracking approach to consumers reaction to olive oil protection brands. In Proceedings Contemporary Trends and Perspectives in Wine and Agrifood Management, Euromed Academy of Business; EuroMed Press: Lecce, Italy, 2015; pp. 357-368.

13. Reitano, A. Il Ruolo Della Tracciabilità Nella Commercializzazione dei Prodotti Agroalimentari; Egea: Milano, Italy, 2012.

14. Folkes, V.; Matta, S. The effect of package shape on consumers' judgments of product volume: Attention as a mental contaminant. J. Consum. Res. 2004, 2, 390-401, doi:10.1086/422117. 